\title{
Vibration Fracture Behavior of Sn-Bi Solder Alloys with Various Bi Contents
}

\author{
Jenn-Ming Song, Yea-Luen Chang, Truan-Sheng Lui* and Li-Hui Chen \\ Department of Materials Science and Engineering, National Cheng Kung University, Tainan 701, Taiwan, R. O. China
}

This study investigated the resonant vibration properties of Sn-Bi solders with hypoeutectic ( $\mathrm{Sn}-10 \mathrm{mass} \% \mathrm{Bi}$ and $\mathrm{Sn}-30 \mathrm{mass} \% \mathrm{Bi}$, referred to as $10 \mathrm{Bi}$ and $30 \mathrm{Bi}$ respectively) and eutectic ( $\mathrm{Sn}-58 \mathrm{mass} \% \mathrm{Bi}$, referred to as $58 \mathrm{Bi}$ ) compositions. Results show that the damping capacity of the 58Bi specimen with continuous distributed eutectic Bi phase was higher than Sn-30Bi, and higher than Sn-10Bi with isolated Bi precipitates. Also, the specimens with higher damping capacity possessed greater vibration fracture resistance under a fixed vibration force. When the vibration was conducted with a constant initial deflection, the vibration fracture resistance decreased in the order of 30Bi, 10Bi and 58Bi. Interfriction at eutectic $\mathrm{Sn} / \mathrm{Bi}$ phase boundaries can be regarded as an effective mechanism in absorbing vibration energy. In the case of $58 \mathrm{Bi}$ and $30 \mathrm{Bi}$, the crack propagated mainly along eutectic-Bi/Sn interfaces and occasionally through the eutectic Bi. As for the $10 \mathrm{Bi}$ specimen, the crack propagation path was mainly intergranular and this can be attributed to fast crack linking by Bi precipitates on the eutectic cell boundaries. In addition, microstructural coarseness caused by artificial aging reduced the area and continuity of eutectic $\mathrm{Sn} / \mathrm{Bi}$ interfaces and thus decrease damping capacity and change the crack propagation morphology.

(Received September 26, 2003; Accepted December 11, 2003)

Keywords: tin-bismuth, vibration, damping capacity, crack growth

\section{Introduction}

The development of $\mathrm{Pb}$-free solders has become an important issue for electronic interconnection materials because of the health and environmental concerns involved with lead usage. Several promising lead-free solders to replace lead-containing solders in microelectronic applications have been proposed and investigated. However, understanding of these new materials is still in its infancy compared to lead-containing solders, and thus further studies are needed.

The Sn-Bi eutectic solder is already used as a lead-free solder for applications at relatively low temperatures in the assembly of electronic devices. Much work has focused on this alloy system. The properties such as wettability, ${ }^{1,2)}$ microstructural coarsening, ${ }^{3,4)}$ creep ${ }^{5-8)}$ strain rate sensitivity $^{9)}$ and fillet lifting ${ }^{10,11)}$ have been concerned and studied. Given that plastic deformation, even failure, may occur due to vibration when solder joints are assembled in automobile vehicles and aircraft, ${ }^{12,13}$ in particular when the vibration frequency meets the resonant vibration of the structure, obviously, the vibration fracture resistance of the solder should be taken into consideration during alloy design. Relevant studies ${ }^{14-18)}$ show that striated deformation in Snrich phase plays an important role in absorbing vibration energy and crack growth in Sn base solder alloys. However, the vibration deformation properties of $\mathrm{Sn}-\mathrm{Bi}$ solders are still not well understood.

This study aimed to explore the vibration fracture behaviors of binary Sn-Bi solder alloys, especially the effect of $\mathrm{Bi}$ content and microstructural coarsening.

\section{Experimental Procedures}

The Sn-Bi alloys investigated were hypoeutectic alloys with compositions of $\mathrm{Sn}-10$ mass $\% \mathrm{Bi}$ and $\mathrm{Sn}-30$ mass\%Bi (referred to as $10 \mathrm{Bi}$ and $30 \mathrm{Bi}$ ), and a eutectic alloy with the

*Corresponding author, E-mail: samsong@url.com.tw composition of $\mathrm{Sn}-58$ mass\%Bi (designated as 58Bi). All the samples were cast using a Y-shaped graphite mold. All the specimens were naturally aged at room temperature to stabilize the microstructure before testing. In addition, some of the 58Bi samples were artificially aged at $100^{\circ} \mathrm{C}$ for 24 hours in an oil bath to obtain specimens with coarse structure, which we will refer as 58Bi-AA.

In order to collect tensile data for reference, rectangular specimens (gauge length section: $20 \mathrm{~mm} \times 5 \mathrm{~mm} \times 2 \mathrm{~mm}$ ), were also prepared to perform tensile tests, (initial strain rate: $\left.7.5 \times 10^{-4} \mathrm{~s}^{-1}\right)$. Each datum was the average of three tests.

A simple cantilever beam vibration system, as shown schematically in Figure 1(a), was used for the vibration experiment. The test specimens, Fig. 1(b), rectangular with dimensions $20 \mathrm{~mm} \times 100 \mathrm{~mm} \times 4 \mathrm{~mm}$ and two $\mathrm{V}$-notches near the clamp, were clamped on end to the vibration shaker. The resonant vibration tests were conducted at either a fixed vibration force $(2.5 \mathrm{~g}$, where $\mathrm{g}$ denotes the acceleration due to gravity, $9.8 \mathrm{~m} / \mathrm{s}^{2}$ ) or a fixed initial deflection (ID) under resonant vibration conditions. The variation in deflection amplitude against cyclic number was recorded. Each datum was the average of results from more than 3 samples.

To understand the crack propagation due to vibration deformation, crack tortuosity and crack branching were quantified, as illustrated in Fig. 2. Crack tortuosity is defined as the ratio of the length of the main crack to the projected length of this crack along the transverse direction of the specimen. The crack branching factor is the ratio of the length of all branched cracks alongside the main crack to the projected length of the main crack. Each datum was the average of results from 5 samples.

Damping capacity was measured in terms of logarithmic decrement ( $\delta$ value) which was derived from the deflection amplitude decay of a specimen under free vibration. Logarithmic decrement value is defined as follows: ${ }^{19)}$

$$
\delta=1 / n \ln \left(A_{i} / A_{i+n}\right)
$$

where $A_{i}$ and $A_{i+n}$ are the deflection amplitude of the $i$ th cycle and the $(i+n)$ th cycle separated by $n$ periods of oscillation. 


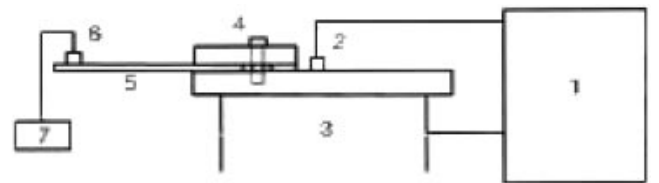

(a)
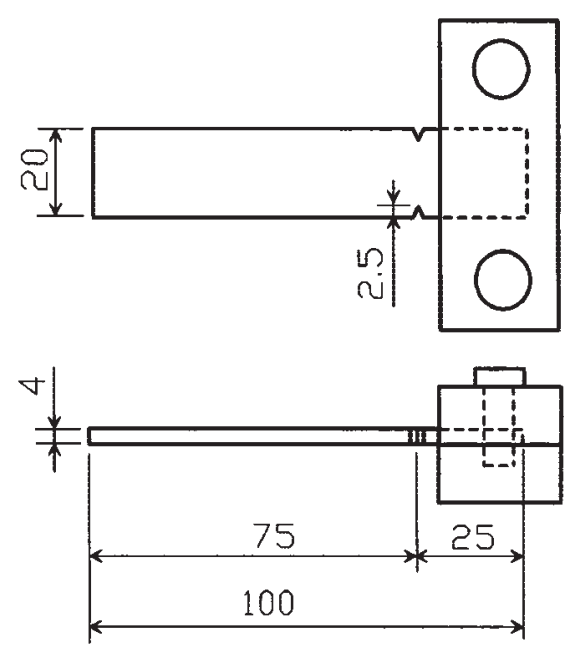

(b)

Fig. 1 (a) The vibration apparatus (1. vibration controller; 2 . acceleration sensor; 3. vibration shaker; 4. specimen clamp; 5. specimen; 6. deflection sensor; 7. recorder), (b) the dimension of test specimens (unit: $\mathrm{mm}$ ).

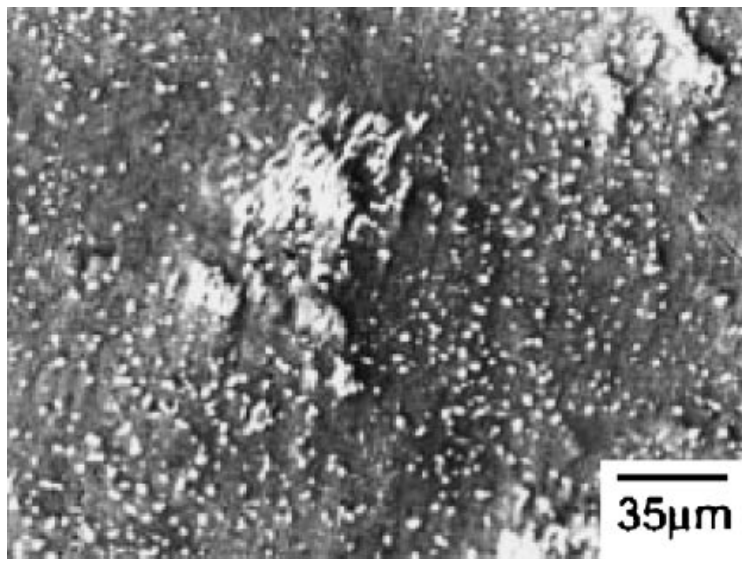

(a)

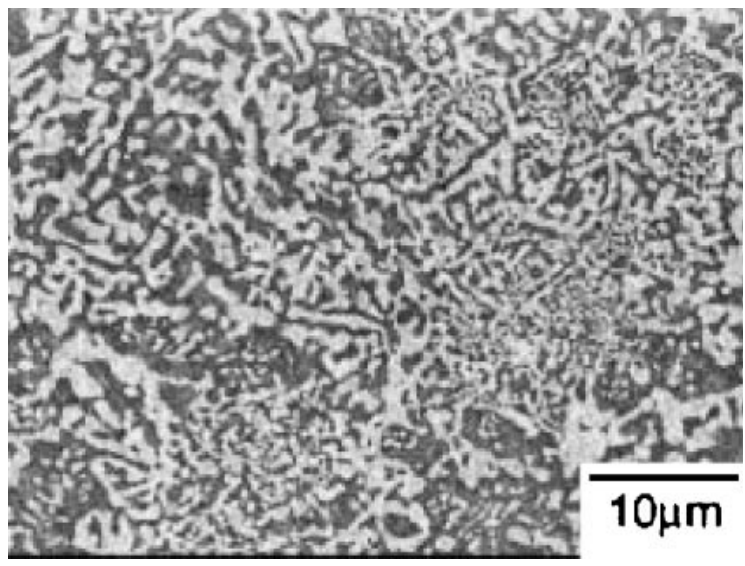

(c)

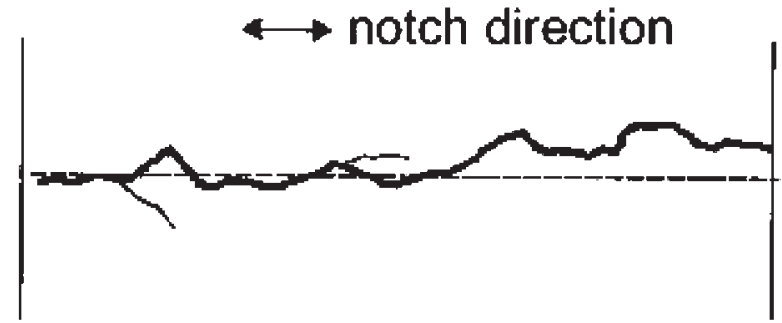

main crack length : Lm

branched crack length: Lb

- - - projected crack length : Lp along notch direction

crack path tortuosity $=\mathrm{Lm} / \mathrm{Lp}$

crack branching factor $=L b / L p \times 100 \%$

Fig. 2 Definition of crack path tortuosity and branching factor.

\section{Results}

Figures 3(a)-(d) show the microstructure of the Sn-Bi alloys investigated in this study. With an increased $\mathrm{Bi}$ content, the amount of $\mathrm{Bi}$ phase became greater. The isolated Bi nodules distributed uniformly in Sn matrix, Fig. 3(a), were precipitated from $\mathrm{Sn}$ matrix. When the Bi content was raised

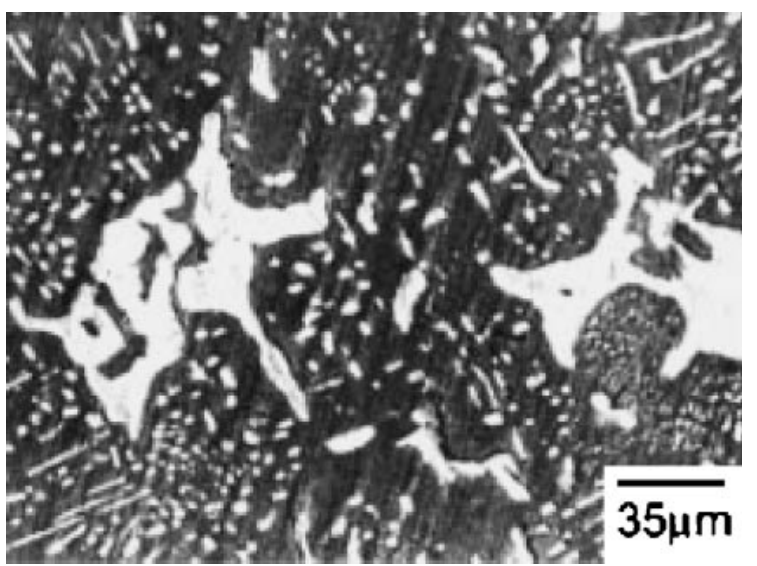

(b)

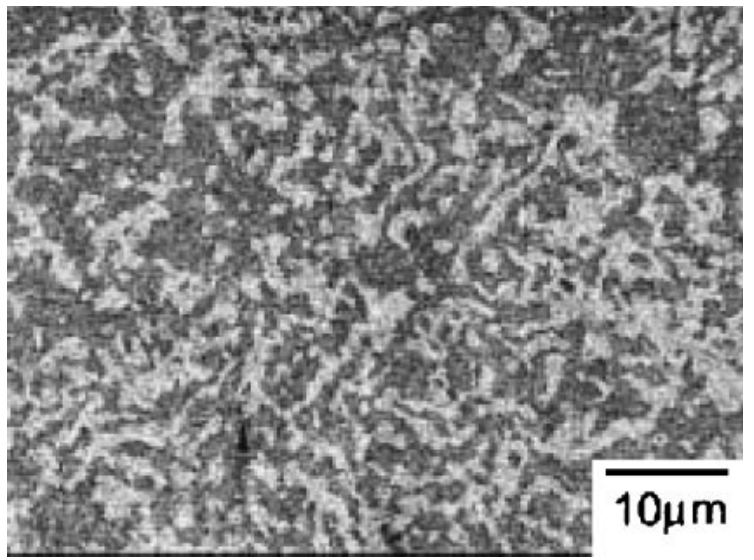

(d)

Fig. 3 Microstructure of (a) 10Bi, (b) 30Bi, (c) 58Bi and (d) 58Bi-AA specimens. 


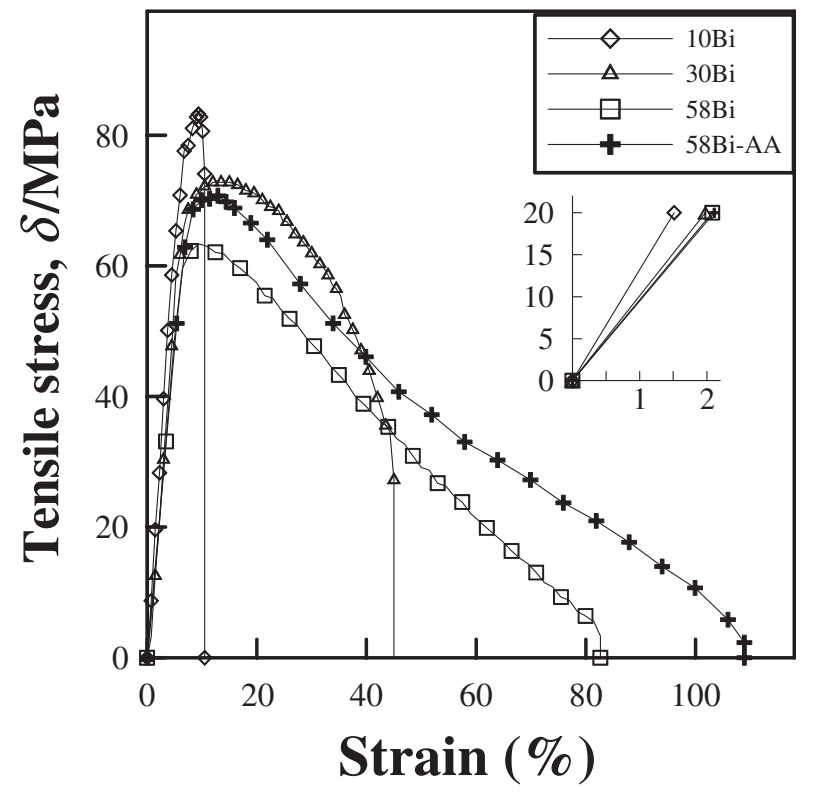

Fig. 4 Stress-strain curves of the specimens.

Table 1 Tensile properties.

\begin{tabular}{cccc}
\hline specimen & $\begin{array}{c}\text { UTS } \\
(\mathrm{MPa})\end{array}$ & $\begin{array}{c}\text { YS } \\
(\mathrm{MPa})\end{array}$ & $\begin{array}{c}\text { EL. } \\
(\%)\end{array}$ \\
\hline $10 \mathrm{Bi}$ & 82.1 & 60.4 & 13.2 \\
$30 \mathrm{Bi}$ & 73.4 & 59.3 & 42.5 \\
$58 \mathrm{Bi}$ & 63.3 & 55.8 & 81.3 \\
$58 \mathrm{Bi}-\mathrm{AA}$ & 69.7 & 58.41 & 105.5 \\
\hline
\end{tabular}

to 30 mass \%, Fig. 3(b), some eutectic Bi phase appeared and the shape of $\mathrm{Bi}$ precipitates changed to be rod-like with rounded ends. Figure 3(b) shows the microstructure of the $58 \mathrm{Bi}$ specimen, illustrating a continuous network of eutectic $\mathrm{Bi}$ phase and Sn-rich grain with fine Bi precipitates. After a high temperature aging at $100^{\circ} \mathrm{C}$ for 24 hours, fine $\mathrm{Bi}$ precipitates in the aged 58Bi sample (58Bi-AA in Fig. 3(d)) dissolved and the eutectic $\mathrm{Bi}$ phase became coarser and more discrete.

Typical tensile stress-strain curves and tensile properties of these Sn-Bi alloys are shown in Fig. 4 and Table 1 respectively. As indicated, the strength decreased in turn from $10 \mathrm{Bi}, 30 \mathrm{Bi}, 58 \mathrm{Bi}-\mathrm{AA}$ to $58 \mathrm{Bi}$. The greatest elongation, $105.5 \%$, occurred in the 58Bi-AA specimen, while the $10 \mathrm{Bi}$ specimen exhibited the least elongation of $13.2 \%$. Notably, the slope of the curve within the elastic region decreases with increasing Bi content.

The dependence of deflection amplitude on the number of vibration cycles (D-N curve) for a fixed vibration force of $2.5 \mathrm{~g}$ or a fixed initial deflection (ID) are shown in Figs. 5(a) and (b), respectively. The frequencies applied in each case are shown in Table 2. Accordingly, at first the deflection amplitude remained nearly constant, as the vibration cycles were increased, sometimes with and sometimes without an initial ascending stage, but subsequently the deflection amplitude decreased with increasing vibration cycles due to the deviation of the actual vibration frequency from the resonant frequency caused by the inward propagation of

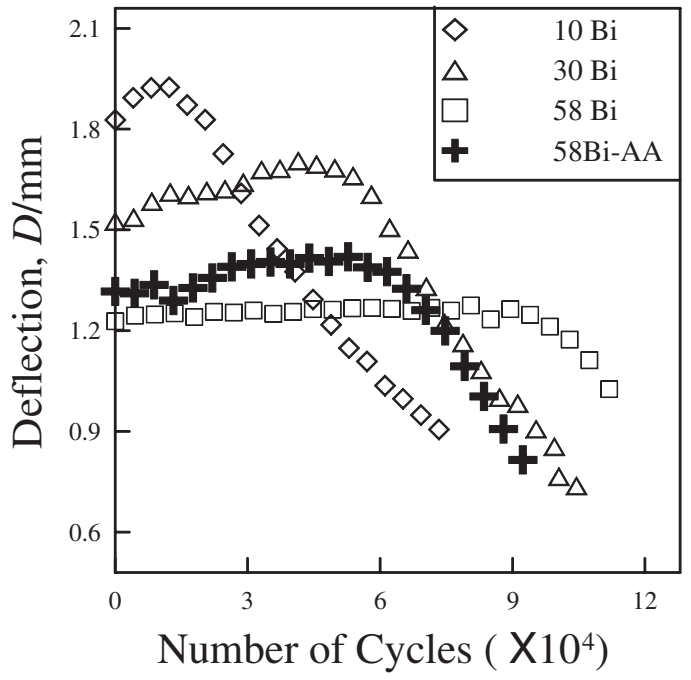

(a)

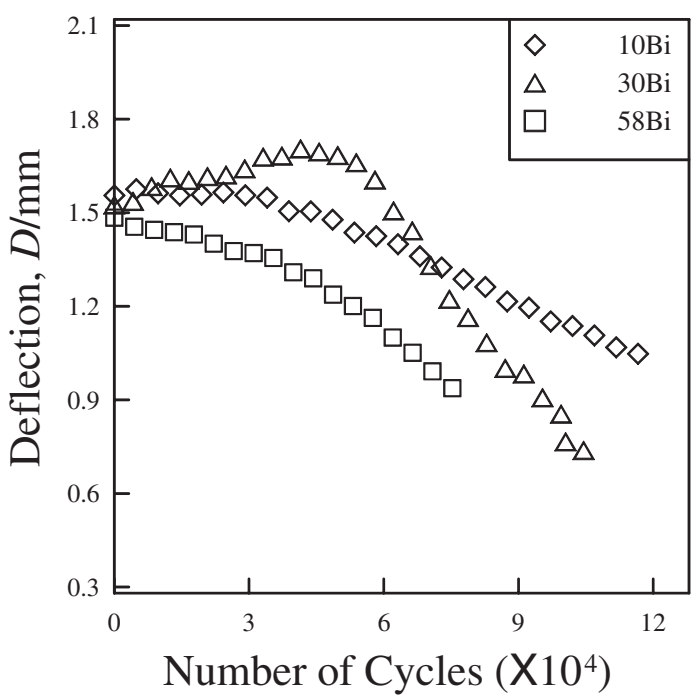

(b)

Fig. 5 D-N curves of the samples (a) under a fixed vibration force of $2.5 \mathrm{G}$ (G: $9.8 \mathrm{~m} / \mathrm{sec}^{2}$ ) and (b) under a fixed initial deflection of $1.5 \mathrm{~mm}$.

Table 2 Resonant frequencies and logarithmic decrement of the specimens.

\begin{tabular}{cccc}
\hline Specimen & $\begin{array}{c}\text { Frequency }(\mathrm{Hz}) \\
\text {-const. force }\end{array}$ & $\begin{array}{c}\text { Frequency }(\mathrm{Hz}) \\
\text {-const. ID }\end{array}$ & $\begin{array}{c}\text { Logarithmic } \\
\text { decrement }\end{array}$ \\
\hline $10 \mathrm{Bi}$ & $80 \pm 1$ & $78 \pm 1$ & 0.187 \\
$30 \mathrm{Bi}$ & $76 \pm 1$ & $76 \pm 1$ & 0.256 \\
$58 \mathrm{Bi}$ & $73 \pm 1$ & $74 \pm 1$ & 0.278 \\
$58 \mathrm{Bi}-\mathrm{AA}$ & $73 \pm 1$ & - & 0.272 \\
\hline
\end{tabular}

major cracks. ${ }^{20,21)}$ Therefore, the vibration life of a sample can be defined as the number of cycles at the beginning of descending deflection amplitude. ${ }^{22)}$

As illustrated in Fig. 5(a), the initial deflection of the specimens in decreasing order was $10 \mathrm{Bi}, 30 \mathrm{Bi}, 58 \mathrm{Bi}-\mathrm{AA}$ and $58 \mathrm{Bi}$, which was inversely proportional to the damping capacity (Table 2) and vibration life (Fig. 6). This indicates that under constant-force conditions a sample with a higher damping capacity possesses a lower initial deflection ampli- 


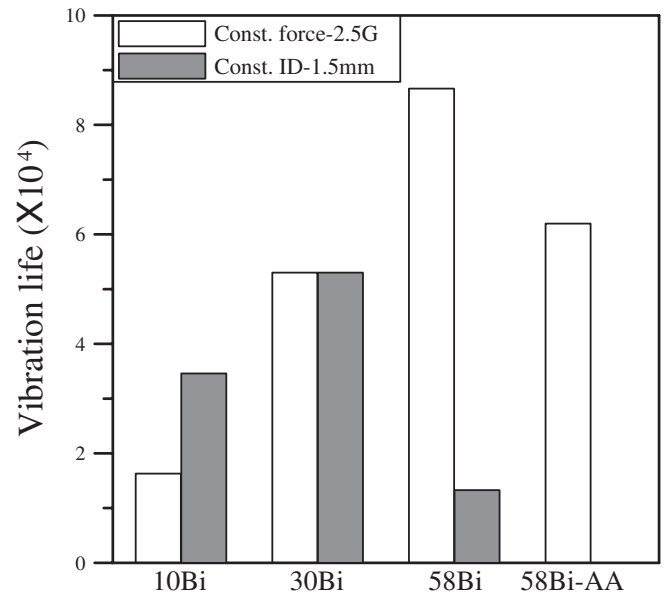

Fig. 6 Critical number of vibration cycles to failure of the samples.

tude and a greater vibration fracture resistance. D-N curves and the vibration lives calculated from them, shown in Fig. 5(b) and Fig. 6, show the results of vibration testing performed under a constant initial deflection amplitude, indicating that the critical number of cycles to failure for $30 \mathrm{Bi}$ was higher than $10 \mathrm{Bi}$, which was in turn higher than $58 \mathrm{Bi}$.

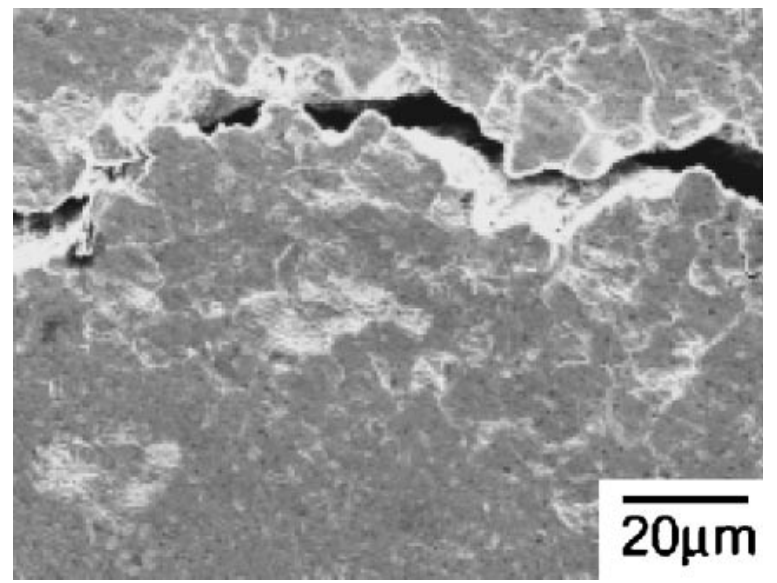

(a)

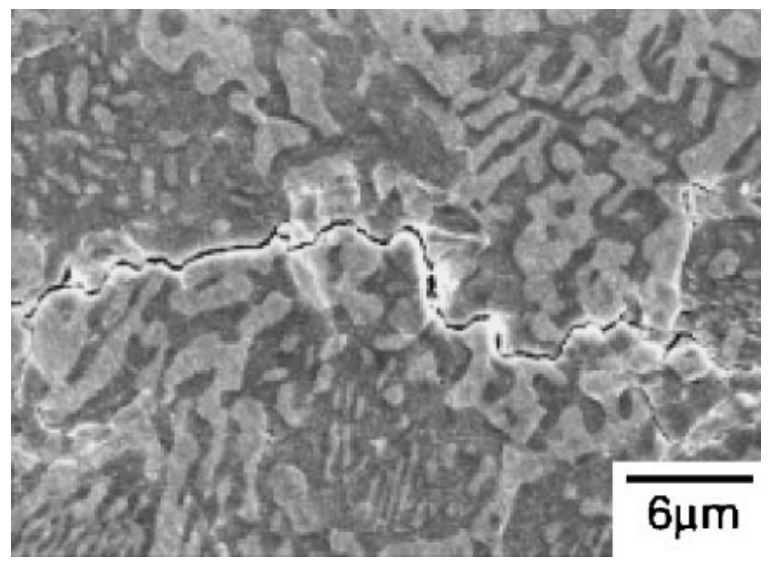

(c)
The crack propagation morphologies and vibration deformed structures of the samples after vibration tests are shown in Figs. 7 and 8, revealing that the deformation structure was quite different depending on the microstructural features of the solders. Figure 7(a) illustrates that the main crack of the 10Bi sample propagated with numerous branched cracks. Also, localized striated deformation was observed in the Sn-rich regions (Fig. 8(a)). Figure 7(b) reveals that the crack branching and striated deformation mentioned above were suppressed in the $30 \mathrm{Bi}$ specimen. The magnified microstructure shown in Fig. 8(b) displays that the main crack passed through the rod-like $\mathrm{Bi}$ precipitates, eutectic Bi and partially along the interfaces of eutectic Bi phase and the matrix. Interestingly, interphase displacements appeared between eutectic $\mathrm{Bi}$ and $\mathrm{Sn}$ interfaces in the 30Bi and 58Bi specimens (Figs. 8(b) and (c)). Moreover, in the case of artificially aged 58Bi sample, Figs. 7(d) and 8(d), the main crack grew through eutectic Bi phase, and a limited zone of striated deformation-feature Sn phase can be found. Quantitative data shown in Table 3 indicates that the crack tortuosity remained constant in all the specimens, except for the 10Bi sample under constant ID conditions, which had a relatively higher value. And, the branching factor tended to be greater with decreasing $\mathrm{Bi}$ content. Under constant force conditions, there was less crack branching after artificial

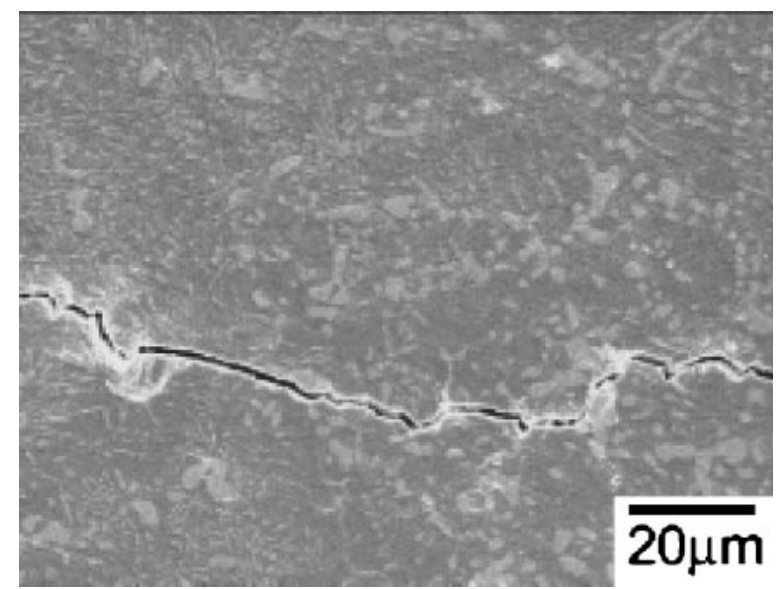

(b)

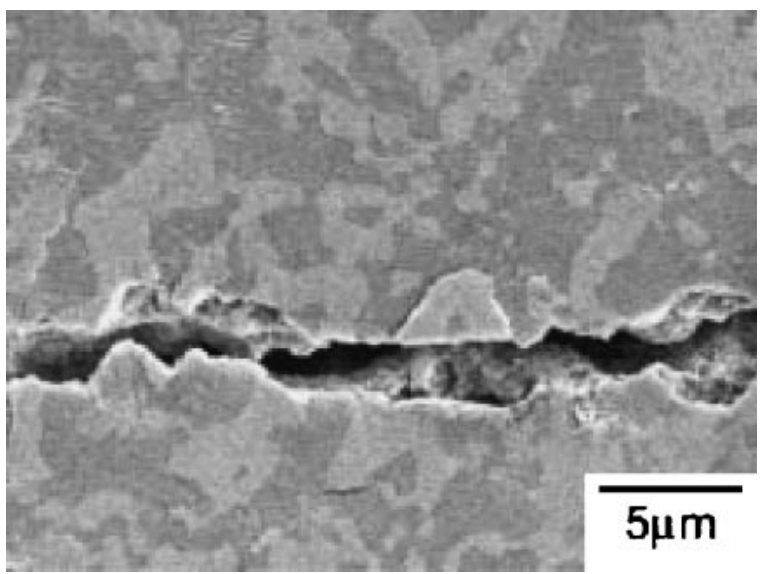

(d)

Fig. 7 Crack growth morphology of the samples vibrated with $2.5 \mathrm{G}$ (a) $10 \mathrm{Bi}$, (b) $30 \mathrm{Bi}$, (c) $58 \mathrm{Bi}$ and (d) $58 \mathrm{Bi}-\mathrm{AA}$. 


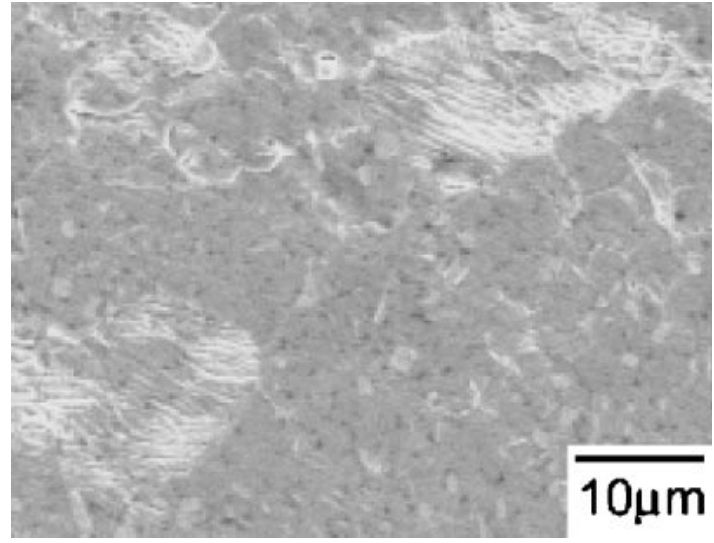

(a)

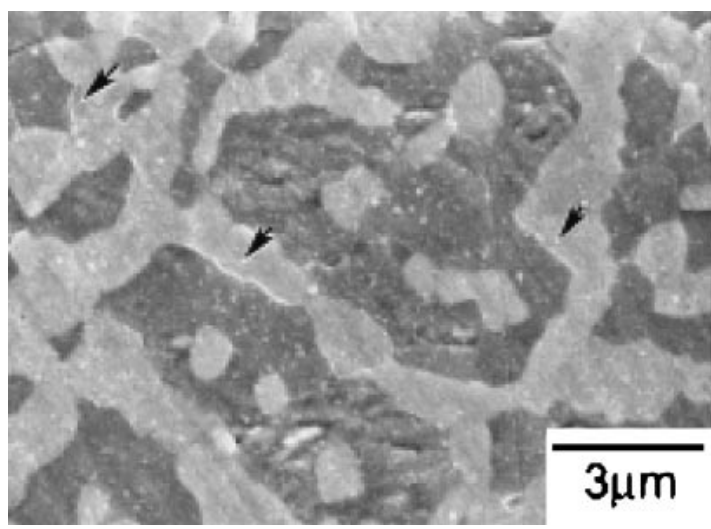

(c)

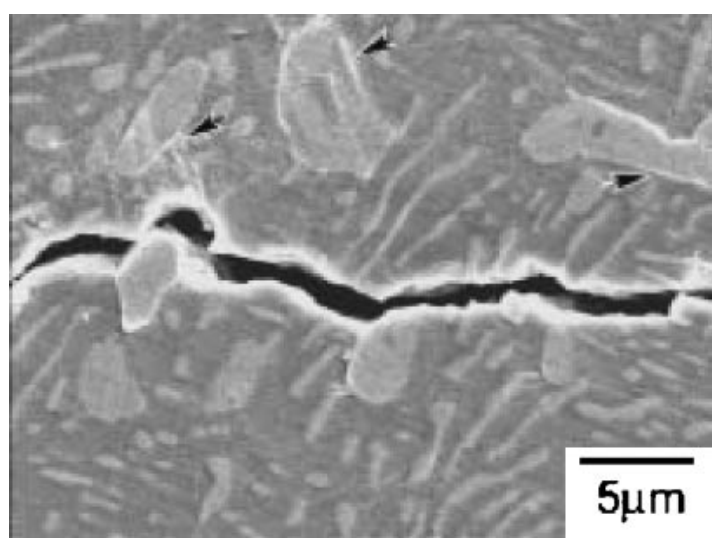

(b)

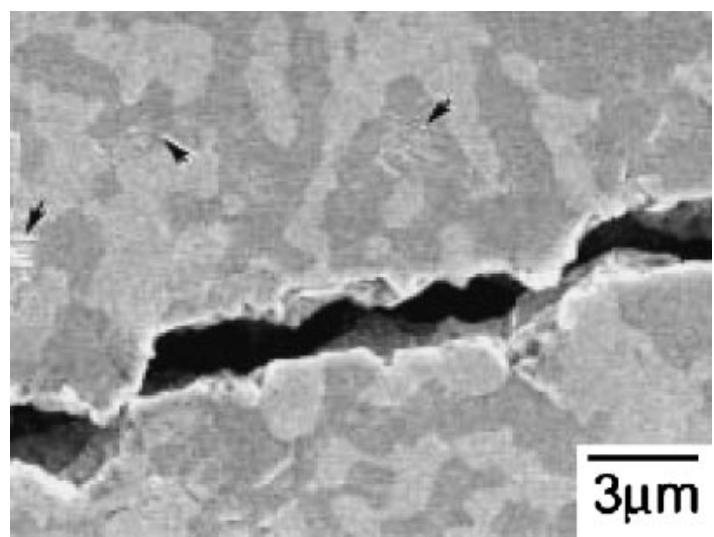

(d)

Fig. 8 Vibration deformed structure in the vicinity of main crack: (a) 10Bi, (b) 30Bi (displacements at interfaces are indicated by arrows), (c) 58Bi (the arrows indicate displacements) and (d) 58Bi-AA (localized striated deformation regions are indicated by arrows).

Table 3 Tortuosity and branching factor (B.F.)

\begin{tabular}{ccccc}
\hline & \multicolumn{2}{c}{ Const. force } & \multicolumn{2}{c}{ Const. ID } \\
& Tortuosity & B.F. (\%) & Tortuosity & B.F. (\%) \\
\hline $10 \mathrm{Bi}$ & 1.019 & 27.01 & 1.138 & 21.64 \\
$30 \mathrm{Bi}$ & 1.031 & 14.71 & 1.031 & 14.71 \\
$58 \mathrm{Bi}$ & 1.037 & 6.99 & 1.034 & 4.69 \\
$58 \mathrm{Bi}-\mathrm{AA}$ & 1.031 & 5.62 & & \\
\hline
\end{tabular}

aging.

Figure 9 displays the fracture surface of the specimens. A partially intergranular fracture can be seen in the fractured 10Bi sample, while fractured $\mathrm{Bi}$ facets can be observed in both the 30Bi and 58Bi samples.

\section{Discussion}

\subsection{Microstructural differences with respect to $\mathrm{Bi}$ con- tent and aging conditions}

Results show that Bi content and aging conditions, which both affect the vibration behavior, yield a number of microstructural changes. As mentioned in a previous report, ${ }^{11)}$ the $10 \mathrm{Bi}$ specimen didn't allow the formation of eutectic phase. This is predicted by the phase diagram in which eutectic phase is only expected to appear beyond
21 mass \% Bi. ${ }^{23)}$ Also, Bi has significant solubility in Sn at the eutectic temperature. Therefore, the fine isolated Bi nodules observed in the 10Bi specimen can be regarded as precipitates from $\mathrm{Sn}$ solid solution in the solid state. When the Bi content was increased from 10 mass $\%$ to 30 mass $\%$, and then to 58 mass $\%$, a eutectic structure with complicated morphology appears locally and then spreads as a continuous network. Microstructural changes due to artificial aging were dissolution of Bi precipitates and coarsening of eutectic $\mathrm{Bi}$. A previous investigation ${ }^{4)}$ indicates that solid-solution hardening by dissolved $\mathrm{Bi}$ in $\mathrm{Sn}$ may overcome softening resulting from microstructural coarsening.

\subsection{Microstructural effect on resonant frequency and damping mechanism}

Table 2 shows that the resonant frequency of the samples in each testing condition tended to reduce with a higher $\mathrm{Bi}$ content. McGuire et al. ${ }^{24,25)}$ reported that the resonant frequency of materials depends on the effective elastic modulus, density and dimensions of the specimen. From the slope of the tensile stress-strain curves, Fig. 4, an increase in $\mathrm{Bi}$ content resulted in a lower apparent elastic modulus. Thus, the variation in resonant frequency may be caused either by a change in elastic modulus or by the density difference, or both, since the elastic modulus and density vary simultaneously with a change in composition. 


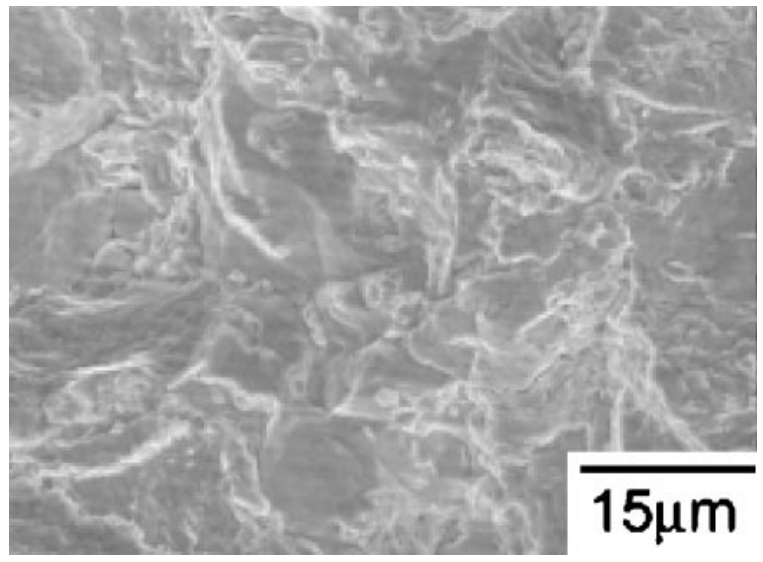

(a)

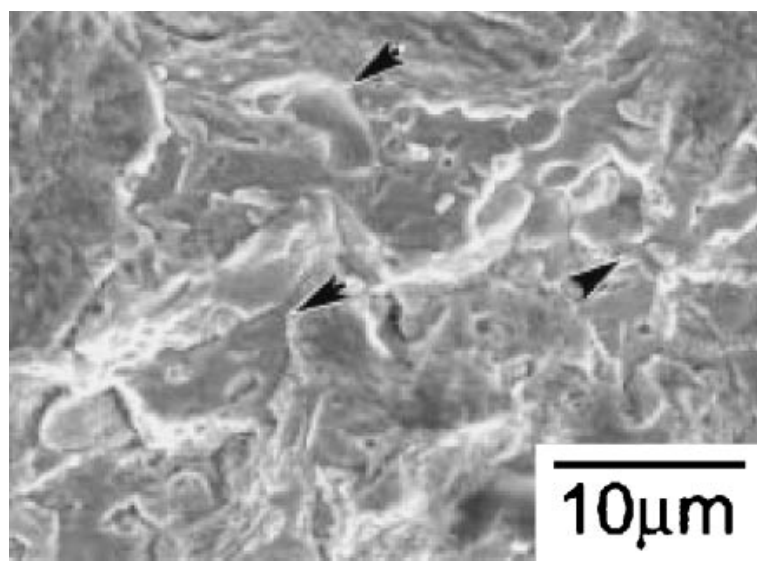

(b)

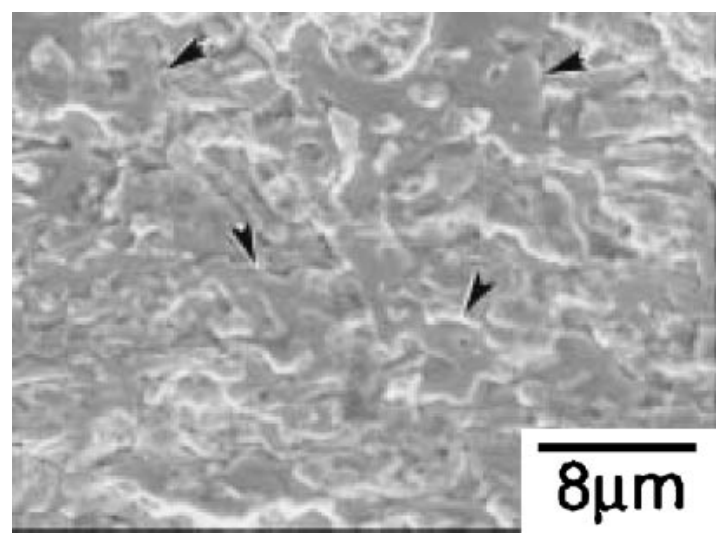

(c)

Fig. 9 Fracture surface of (a) 10Bi, (b) $30 \mathrm{Bi}$ and (c) $58 \mathrm{Bi}$ (Bi phase facets are indicated by arrows).

The relationships between vibration life, logarithmic decrement and initial deflection under $2.5 \mathrm{G}$ conditions, illustrated in Fig. 10, reveal that the vibration life under fixed force conditions is roughly proportional to damping capacity and inversely proportional to the initial strain. This implies that $\mathrm{Sn}-\mathrm{Bi}$ alloys with a higher damping capacity exhibit greater vibration fracture resistance.

With respect to binary Sn-based eutectic solders, the vibration life is also closely related to the damping capacity. A recent study ${ }^{26)}$ indicates that under a fixed vibration force

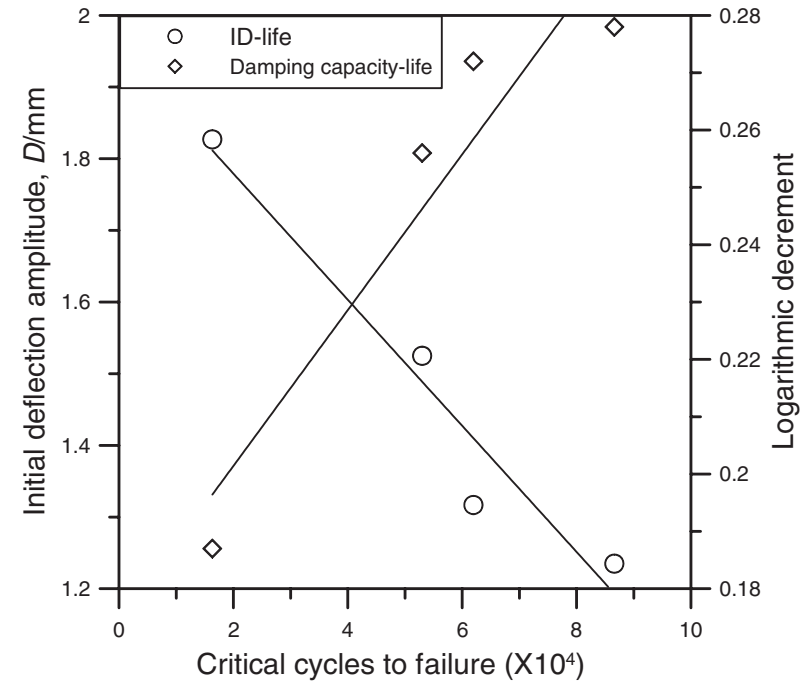

Fig. 10 Initial deflection and Logarithmic decrement against vibration life.

the damping capacity and vibration fracture resistance of Sn$\mathrm{Cu}$ and $\mathrm{Sn}-\mathrm{Ag}$ eutectic alloy with an off-eutectic structure are higher than $\mathrm{Sn}-\mathrm{Pb}$ and are also higher than $\mathrm{Sn}-\mathrm{Bi}$ and $\mathrm{Sn}-\mathrm{Zn}$. This can be deduced that the solders exhibit a dendritic Snmatrix show greater vibration behavior than others.

Our previous studies ${ }^{14-18)}$ reveal that striated deformation in Sn-rich phase is an efficient mechanism for Sn base alloys to dissipate vibration energy. The striated deformation of the $\mathrm{Sn}$-rich phase is a characteristic feature which only appears under high-frequency repeated stress. Its formation is probably due to the extrusion-intrusion of slip planes under cyclic stress. ${ }^{27)}$ However, in the case of the Sn-Bi system investigated in this study, striated deformation didn't occur in every specimen, and the area was quite limited. This could be attributed to the fine $\mathrm{Bi}$ precipitates uniformly distributed in $\mathrm{Sn}$ matrix which stunted the deformation of $\mathrm{Sn}$ phase. In addition, the solubility in equilibrium of $\mathrm{Bi}$ in $\mathrm{Sn}$, about $4 \%$ $\mathrm{Bi}$, definitely hardened the Sn matrix. ${ }^{23)}$

Interphase displacement found at the eutectic $\mathrm{Bi} / \mathrm{Sn}$ interfaces, which was probably caused by phase boundary sliding, ${ }^{8)}$ would significantly contribute to an increase in the ability to absorb vibration energy by interfriction. Consequently, the 58Bi specimen, which possessed a continuous eutectic network, exhibited the greatest damping capacity and thus the lowest initial deflection. As for the 58Bi-AA specimen, coarsening and discontinuity of eutectic Bi phase caused by high temperature storage led to a decrease in damping capacity, even though a limited zone of striated deformation appeared in coarsen Sn phase.

\subsection{Microstructural effect on crack propagation}

As illustrated in Figs. 7(a) and 9(a), the 10Bi specimen shows a partially intergranular fracture morphology and branched crack propagation path. This can be ascribed to the crack propagation along the $\mathrm{Bi}$ precipitates on the $\mathrm{Sn}$ cell boundaries. On the other hand, crack propagation in the eutectic 58Bi sample was along the $\mathrm{Sn} / \mathrm{Bi}$ interface and occasionally through the Bi-rich phase, Fig. 7(c). The eutectic Sn/Bi interface provides a convenient path for crack propagation and thus low fracture resistance. Therefore, 
when the vibration test was conducted with a fixed initial deflection, without the influence of damping capacity, the 30Bi sample with discontinuous eutectic structure and rodlike $\mathrm{Bi}$ precipitates exhibited a higher vibration fracture resistance.

\section{Conclusions}

(1) Compared to hypoeutectic compositions, the Sn-Bi alloy with the eutectic composition of $58 \mathrm{mass} \% \mathrm{Bi}$ possessed a higher damping capacity and a longer vibration life under constant-force conditions.

(2) Due to the fine distribution of $\mathrm{Bi}$ precipitates, the formation of striated deformation in $\mathrm{Sn}$ phase was limited. Interfriction at the eutectic $\mathrm{Sn} / \mathrm{Bi}$ interfaces was probably the mechanism which improved the damping capacity of Sn-Bi alloy.

(3) The vibration life under constant-initial deflection conditions in the decreasing order was $30 \mathrm{Bi}, 10 \mathrm{Bi}$ and 58Bi. Continuous eutectic Sn-Bi interfaces in the 58Bi specimen and intergranular cracking in the 10Bi specimen were respectively responsible for the low crack propagation resistance of $58 \mathrm{Bi}$ and $10 \mathrm{Bi}$ specimens.

(4) High temperature aging gave rise to microstructural changes the in $\mathrm{Sn}-\mathrm{Bi}$ eutectic alloys, namely, the dissolution of $\mathrm{Bi}$ precipitates, and the coarsening and discontinuity of eutectic structure. These led to a slightly lower damping capacity and thus a shorter vibration life under constant force conditions.

\section{Acknowledgments}

This work has been supported by the Chinese National Science Council (Contract: NSC 91-2216-E-006-054), for which the authors are grateful.

\section{REFERENCES}

1) Y. Y. Chen, J. G. Duh and B. S. Chiou: J. Mater. Sci.-Mater. El. 11 (2000) 279-283.

2) C. B. Lee, S. B. Jung, Y. E. Shih and C. C. Shur: Mater. Trans. 42
(2001) 751-755.

3) J. N. Hu, H. Tanaka and T. Narita: Mater. Trans. 42 (2001) 769-775.

4) Y. Miyazawa and T. Ariga: Mater. Trans. 42 (2001) 776-782.

5) J. L. Freer Goldstein and J. W. Morris, Jr.: J. Electron. Mater. 23 (1994) $477-486$.

6) G. S. Al-Ganainy, M. R. Nagy, B. A. Khalifa and R. Afify: Phys. Status Solidi 158 (1996) 463-469.

7) T. H. Alden: Acta Metall. 15 (1967) 469-479.

8) C. H. Raeder, D. Mitlin and R. W. Messler, Jr.: J. Mater. Sci. 33 (1998) 4503-4508.

9) M. McCormack, H. S. Chen, G. W. Kammlott and S. Jin: J. Electron. Mater. 26 (1997) 954-958.

10) W. J. Boettinger, C. A. Handwerker, B. Newbury, T. Y. Pan and J. M. Nicholson: J. Electron. Mater. 31 (2002) 545-550.

11) K. Suganuma: Scr. Mater. 38 (1998) 1333-1340.

12) Q. J. Yang, H. L. J. Pang, Z. P. Wang, G. H. Lim, F. F. Yap and R. M. Lin: Microelectronic Reliability 40 (2000) 1097-1107.

13) Y. Zhao, C. Basaran, A. Cartwright and T. Dishongh: The 7th Intersociety Conference on Thermal and Thermechanical Phenomena in Electronic Systems, 2000, vol. 2, pp. 349-355.

14) C. M. Chuang, T. S. Lui and L. H. Chen: J. Electron. Mater. 30 (2001) $1232-1240$.

15) C. M. Chuang, T. S. Lui and L. H. Chen: Mater. Trans. 42 (2001) 20642070.

16) C. M. Chuang, T. S. Lui and L. H. Chen: J. Mater. Res. 16 (2001) 26442652.

17) C. M. Chuang, T. S. Lui and L. H. Chen: Mater. Trans. 41 (2000) 656662.

18) J. M. Song, G. F. Lan, T. S. Lui and L. H. Chen: Proc. 4th International Symposium on Electronic Materials and Packaging, IEEE-CPMT, Dec. 4-6, 2002, Kaohsiung, Taiwan.

19) R. F. Steidel, Jr., An Introduction to Mechanical Vibrations, Third ed., John Wiley \& Sons Comp., 1989, pp. 169-170.

20) D. S. Jiang, T. S. Lui and L. H. Chen: Scr. Mater. 36 (1997) 15-20.

21) D. S. Jiang, T. S. Lui and L. H. Chen: Mater. Trans. 41 (2000) 499-506.

22) J. M. Song, G. F. Lan, T. S. Lui and L. H. Chen: J. Alloys Compounds, in press.

23) M. Hansen: Constitution of Binary Alloys, (McGraw-Hill Book Company, Inc, New York, 1958).

24) S. M. McGuire, M. E. Fine, O. Buck and J. D. Achenbach: J. Mater. Res. 8 (1993) 2216-2223.

25) S. M. McGuire, M. E. Fine and J. D. Achenbach: Metall. Mater. Trans. 26A (1995) 1123-1127.

26) J. M. Song, T. S. Lui, L. H. Chen and D. Y. Tsai: to appear in J. Electron. Mater., vol. 32, no. 12 (2003).

27) A. Opinsky and R. Smoluchowski: Plastic Deformation in Crystallines Solids, Pittsburgh, (PA, Mellon Institute, 1950), p. 216-223. 